\title{
Failure Analysis of Austenitic Stainless Steel Implant Screws and Prospection of Chemical Composition Using Artificial Intelligence
}

\author{
Alfonso Monzamodeth Román-Sedano ${ }^{*}{ }^{*}$, Bernardo Campillo1,2, Fermín Castillo², \\ Osvaldo Flores ${ }^{1,2}$ \\ ${ }^{1}$ Facultad de Química, Universidad Nacional Autónoma de México, Ciudad de México, México \\ ${ }^{2}$ Instituto de Ciencias Físicas, Universidad Nacional Autónoma de México, Cuernavaca Morelos, México \\ Email: *amrsroman@icf.unam.mx
}

How to cite this paper: Román-Sedano, A.M., Campillo, B., Castillo, F. and Flores, O. (2022) Failure Analysis of Austenitic Stainless Steel Implant Screws and Prospection of Chemical Composition Using Artificial Intelligence. World Journal of Engineering and Technology, 10, 98-118. https://doi.org/10.4236/wjet.2022.101006

Received: January 29, 2022

Accepted: February 22, 2022

Published: February 25, 2022

Copyright $\odot 2022$ by author(s) and Scientific Research Publishing Inc. This work is licensed under the Creative Commons Attribution International License (CC BY 4.0).

http://creativecommons.org/licenses/by/4.0/

(c) (i) Open Access

\begin{abstract}
In this work, austenitic stainless steel screws employed in a locking compression plate for veterinarian use were investigated. These types of implants are widely utilized in bone fractures healing. Two surgical screws were extracted due to the observation of slight superficial red rust colorizing on one of the screw implants, visual evidence of probable screw rusting. From the same implant, another screw was extracted simultaneously without visual evidence of rusting. In order to characterize and analyze the different behavior of both screws, the chemical composition was characterized by atomic absorption and energy dispersive X-ray spectroscopy (EDS) coupled to a scanning electron microscope (SEM). Also, the screws were studied by metallography, optical microscopy (OM), Vickers microhardness tests, and SEM analysis. On the other hand, a prospection for alloy chemical composition limits of these types of implants was performed based on the Schaeffler-Delong diagram and the ASTM F-138 standard. To analyze the effect of the chemical composition, heat treatment, microstructure, pitting resistance equivalent number (PRE) and stacking fault energy (SFE), a genetic algorithm (GA) and an artificial neural network (ANN) were used. In accordance with the elemental analysis, the surgical screws do not fulfill the ranges of the chemical composition established by the ASTM F-138 standard. Furthermore, there were found differences between the microstructures of the screws. In regard to the prospection, the results of GA and ANN support the proposed chemical composition region on the Schaeffler-Delong diagram. The corrosion failure was associated with severe plastic deformation and the presence of precipitates. The proposal can minimize the cause of failures in these types of austenitic stainless steel implants.
\end{abstract}




\section{Keywords}

Implant Screw, Failure Analysis, Genetic Algorithm, Artificial Neural Network, Austenitic Stainless Steel

\section{Introduction}

The austenitic stainless steel is commonly employed in surgical field applications as implants, tools, and prostheses. Customarily these implants are manufactured of 300 type austenitic stainless steel due to its resistance to intergranular and pitting corrosion. Some types of implants are produced under the ASTM-F 138 standard, such control must be fulfilled to avoid intergranular corrosion, high magnetic susceptibility, unwanted microstructural phases, and pitting corrosion [1]-[7]. Several studies have been carried out on this type of steel, such as the effect of heat treatment on microstructural properties, the grain size evolution, and their sensitization response [5] [6] [7] [8] [9]. In addition, the chemical composition and the plastic deformation modify the stacking fault energy (SFE) behavior. The SFE value is an important parameter to consider within the design of austenitic stainless steels due to its direct influence on phase changes, crystal lattice defects and magnetic susceptibility [10]-[15]. On the other hand, artificial intelligence (AI) is a powerful tool capable to provide predicting support to complex behavior in several fields of science and engineering. The genetic algorithm (GA) is a technique within the AI for parametric optimization by the search of solutions based on natural selection, wherewith a given environment the most optimal solution must be adapted and eventually improved. Some GA variations have been employed in several stainless steel's applications, such as machining and heat treatment process, mechanical properties optimization, among others [16] [17] [18]. Also, within AI, artificial neural networks (ANNs) are widely used in several science and technology areas. The ANNs are nonlinear predictive models based on biological neuronal activity, being implemented to predict several properties and behavior based on different parameters [19] [20] [21]. Some authors incorporate applications of GA and ANNs for the optimization of several processes such as thermomechanical, hot and cold compression, welding, etc. [22] [23]. In the present work, screws of a locking compression plate of veterinarian application were studied. Such plating systems are employed to provide stability and fixation to bone fracture healing. The screws used were chirurgical retrieved due to visual rusting evidence reported. Further analysis indicated the presence of localized corrosion and some microstructural features that lead to determining the necessary surgical removal to avoid an infection process. Moreover, based on artificial intelligence (GA and ANNs), a prospection of chemical composition considering the ASTM F-138 SS standard and the Schaeffler-Delong diagram was proposed. The GA was developed to establish ranges of chemical composition that can assist the SS manufacture, to avoid corrosion issues similar 
to the studied in the present work. On the other hand, the ANNs were trained using available database; subsequently the predictive model was employed to evaluate the ranges of chemical composition obtained by the GA. The latter was performed to predict the SFE and relate the possible behavior of the alloys manufactured within the range of chemical composition obtained.

\section{Material and Methods}

\subsection{Implant Screws Extracted}

Locking compression plates are widely used to treat bone fracture. Usually, the implant consists of a plate, and the locking and compression screws. The screws studied in this work had a thread profile with special features for fixation cortical type for osteosynthesis [2] [3] [4]. Originally the reason for the extraction of the screws was the observation of a thin red colored layer in one of them, which may indicate a possible corrosion failure and a probably risk of infection process. Figure 1(a) and Figure 1(b) show the removed screws, and a SEM observation is also presented in Figure 1(c) and Figure 1(d), showing the surface image obtained. It was not possible observe any difference due to the thickness of the rusted layer formed and the regenerative property of the passive layer of chromium oxide, an inherent characteristic of stainless steels (SS). Hence, it was necessary perform a deeper analysis of the material to observe the cause of its failure.

\subsection{Material Characterization}

The material characterization of extracted implants screws has been carried out.
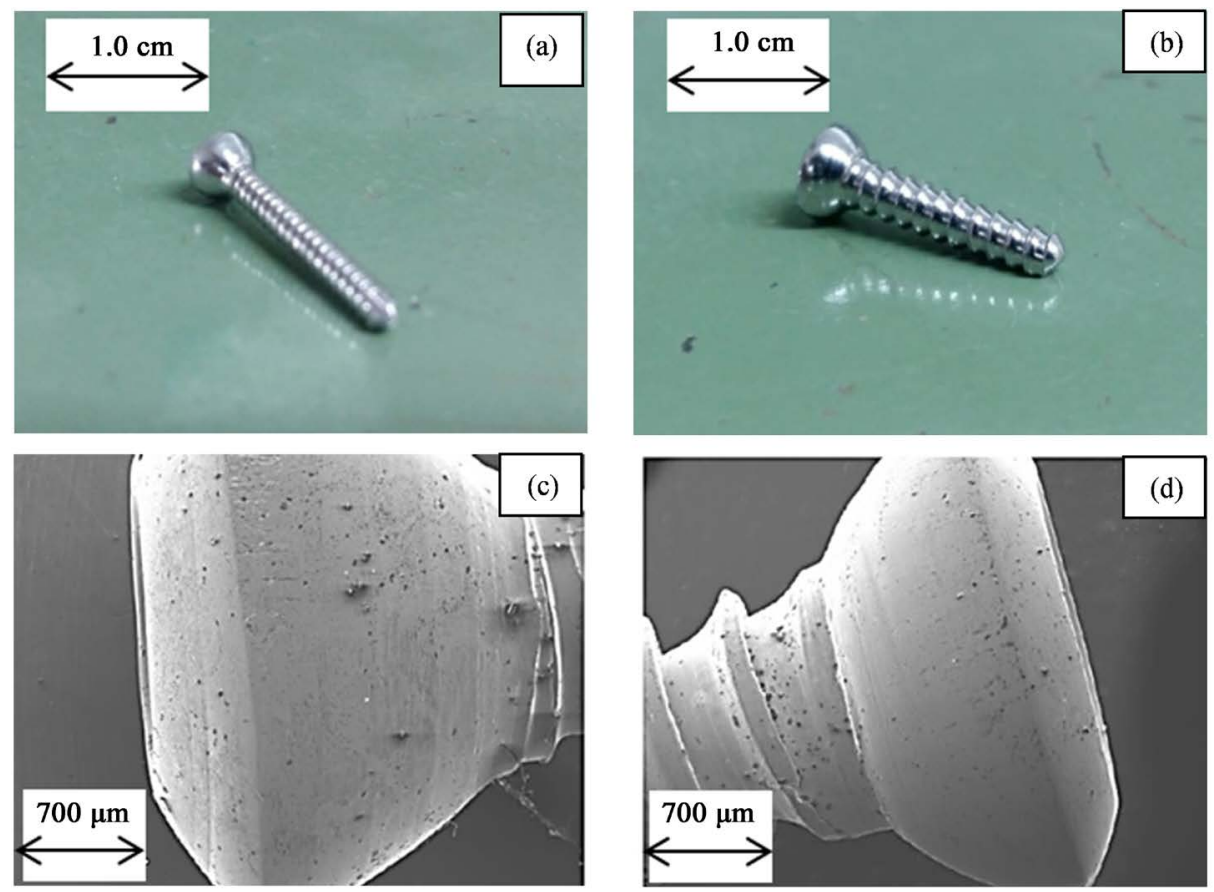

Figure 1. Cortical screws extracted ((a), (c)) large cortical screw with apparent corrosion failure ((b), (d)) short cortical screw uncorroded. 
These implants were reported to be made of AISI 316L stainless steel (ASTM F-138). Characterizations and the failure analysis were performed on corroded and uncorroded screws. The chemical composition was obtained via energy dispersive $\mathrm{x}$-ray spectroscopy (EDS, Oxford INCA) and atomic absorption by induced coupled plasma (ICP, Perkin Elmer), respectively. The results obtained of both techniques are presented in Figure 4 and Table 1. Furthermore, the initial characterization was performed through metallographic analysis; the samples were prepared up to a polished condition and analyzed by OM in light and dark fields. Also, second phase particles (precipitates) were measured over an area of $0.25 \mathrm{~mm}^{2}$ using Image $\mathrm{J}$ software. Subsequently, microstructure was revealed using electrochemical etching with $10 \%$ oxalic acid in aqueous solution. On the other hand, a morphologic analysis was performed using the scanning electron microscopy (SEM JEOL, $5900 \mathrm{LV}$ ) coupled with EDS detector for elemental mapping. Finally, the Vickers microhardness of the screws was performed, and the selected load used was 200 gf in a microhardness tester Matsuzawa.

\subsection{Prospection of Chemical Composition}

\subsubsection{Genetic Algorithm Conditions}

On the Schaeffler-Delong diagram, as shown in Figure 2 was delimited a region that comply the elemental chemical range established by the ASTM-F 138 standard.

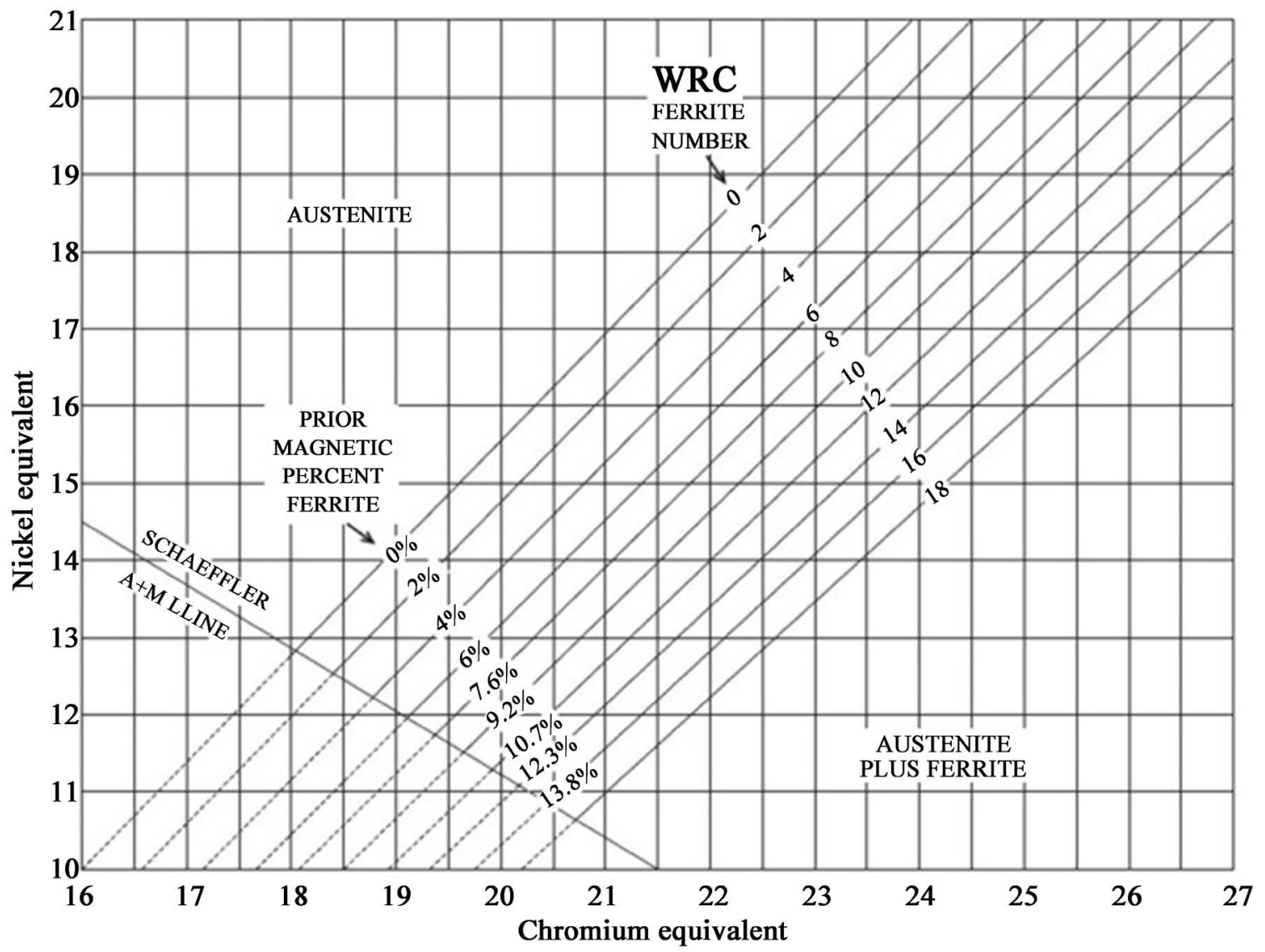

Figure 2. Schaeffler-Delong diagram. 
This diagram is composed by two hyperplane Equations: (1) the chromium equivalent $\left(\mathrm{Cr}_{\mathrm{E}}\right)$ and Equation (2) nickel equivalent $\left(\mathrm{Ni}_{\mathrm{E}}\right)$. The Equation (1) involves chemical elements ( $\mathrm{Cr}$ and $\mathrm{Mo}$ ), necessary for the calculus of pitting resistance equivalent (PRE) number, which is required in the standard (see Equation (3)) [3]. A genetic algorithm was performed in order to develop and to find an optimal solution for the chemical composition range using the hyperplane equations and PRE values. The equations used for establishing the restrictions of the genetic algorithm are shown.

$$
\begin{gathered}
\mathrm{Cr}_{\mathrm{E}}=\% \mathrm{Cr}+\% \mathrm{Mo}+(1.5 * \% \mathrm{Si})+(0.5 * \% \mathrm{Nb}) \\
\mathrm{Ni}_{\mathrm{E}}=\% \mathrm{Ni}+(30 * \% \mathrm{C})+(0.5 * \% \mathrm{Mn})+(30 * \% \mathrm{~N}) \\
\mathrm{PRE}=\% \mathrm{Cr}+(3.3 * \% \mathrm{Mo})
\end{gathered}
$$

Equations (1), (2) and (3) were taken as objective functions under the imposed restrictions by ASTM-F-138 standard and the austenitic region defined by Schaeffler-Delong diagram. The aforementioned consideration was selected in an ideal condition, which the steel must be composed of a completely austenitic phase due to the required corrosion resistance properties [3] [4] [5]. The used genetic operators are shown below:

- Population size: 1000 .

- Search range: established considering the ASTM F-138 standard (individual range for each chemical element was selected considering the Schaeffler-Delong diagram and PRE values).

- Number of generations limit: 1000.

- Limit value of fitting function: $1 \mathrm{E}-3$.

- Crossing probability: $90 \%$.

- Mutation probability: $2 \%$.

\subsubsection{Mapping of the Proposed Chemical Composition Using ANNs}

An ANN was developed to mapping the region obtained through GA. Based on three heat treatments and the chemical composition studied by [5], the ANN was trained and reported previously [3]. In the present work, heat treatment effect on the SFE value was analyzed for three microstructural conditions: solubilization heat treatment water/cooling (SHTWC), solubilization heat treatment furnace/cooling (SHTFC) and aging treatment (AGG) based on the above mentioned authors. Figure 3 shows the designed architecture for the predictive model consisting of an input layer composed by nine chemical elements, one hidden layer and an output layer for a SFE value prediction of SHTWC, SHTFC and AGG conditions. Each neuron is constituted by the hyperbolic activation function (Equation (4)) and input values $\left(X_{i}\right)$, see Equation. 5. The weights and biases are represented as $W_{i}$ and $\theta$ respectively. In order to accomplish the training process, the database was normalized from 0 to 1 . The error was calculated using the mean square error (MSE) and for the ANN training the Levenberg-Marquardt algorithm was implemented [24]. 


$$
\begin{gathered}
f(x)=\frac{2}{1+\exp ^{-2 x}}-1 \\
x=\sum_{i=1}^{n} X_{i} W_{i}+\theta
\end{gathered}
$$

\section{Results}

\subsection{Energy Dispersive X-Ray Spectroscopy}

The qualitative analysis via energy dispersive $\mathrm{x}$-ray spectroscopy (EDS) showed the same main alloy elements (Fe-Cr-Ni-Mo) in both implant screws corresponding to an austenitic stainless steel 316. In Figure 4(a) and Figure 4(b) are

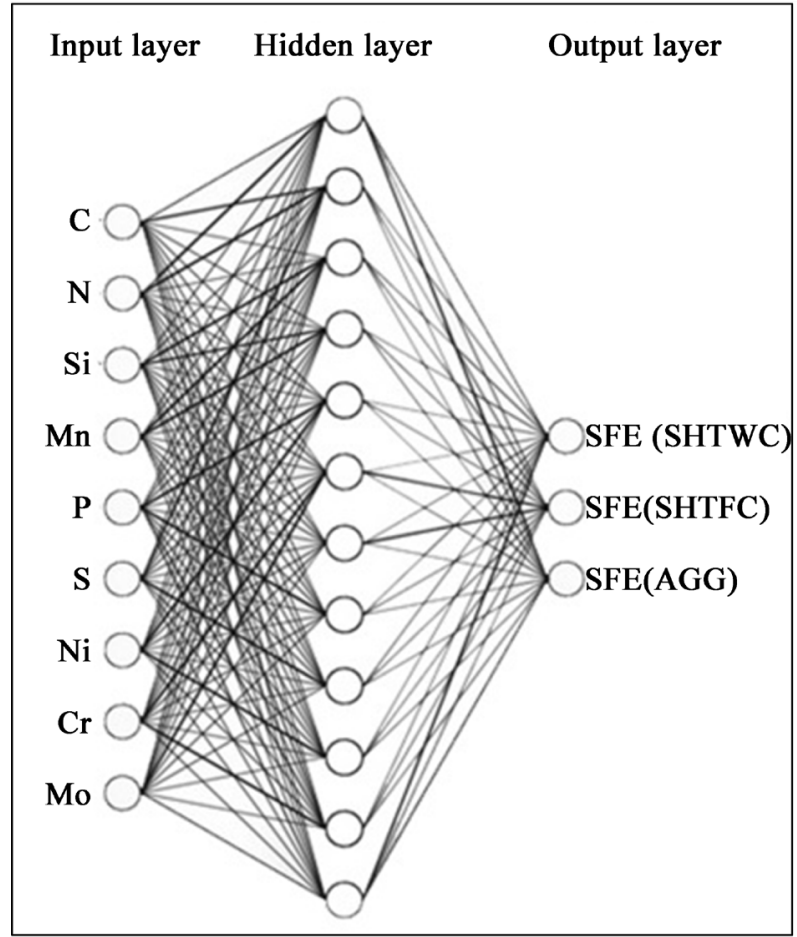

Figure 3. Architecture of the ANN.
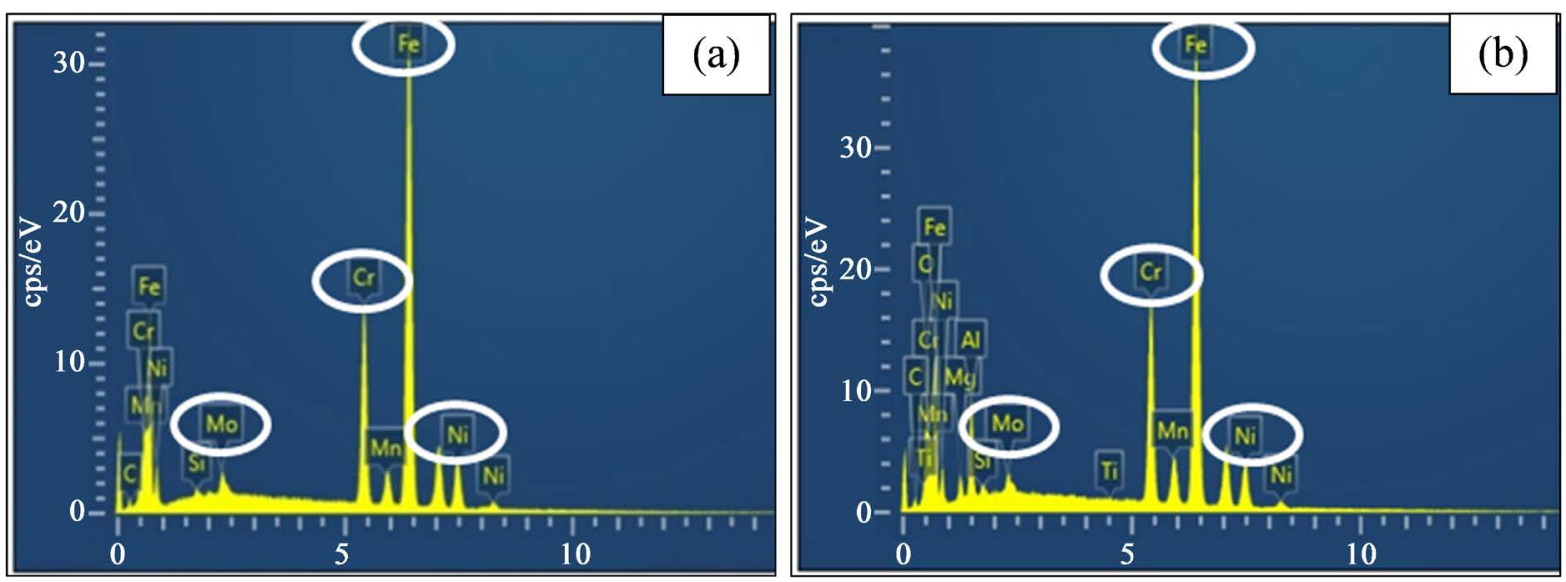

Figure 4. EDS spectra a) corroded implant screw, b) uncorroded implant screw. 
the spectra obtained of the two implants. The initially suspected failure cause was a misusage of a similar material like SS 304 instead SS 316, however, the EDS analysis confirmed that both screws correspond to the SS 316. It is clear from the EDS results that are not suitable to analyze very thin surface layers, which do not distinguish between corroded and uncorroded samples, it was necessary to perform further analyses using other characterization techniques.

\subsection{Atomic Absorption}

The Once confirming the presence of alloy elements, a quantitative chemical analysis was performed. Table 1 shows the atomic absorption results, showing that the chemical composition of the screws is out of ASTM F-138 standard range (bolded in Table 1). It can be seen that the corroded implant screw has higher content of the main elements of the austenitic SS alloy as established in the ASTM F-138 standard. Additionally, PRE values were calculated for both screws as shown in Table 1. It was found that the corroded screw provides higher PRE value than uncorroded, which according to the standard must depict better corrosion resistance. However, if there are higher amounts of alpha phase stabilizer elements such as Cr, thus the PRE value does not guarantee that the SS has greater corrosion resistance because a probable formation of fine precipitates and $\alpha$ phase [3] [4] [5]. Thereby, the atomic absorption results confirmed the lower resistance to pitting corrosion of the corroded screw even it has higher $\mathrm{Cr}$ equivalent number value.

Table 1. Results of the quantitative elemental analysis of the uncorroded and corroded screws.

\begin{tabular}{|c|c|c|c|}
\hline Alloy element & $\begin{array}{c}\text { ASTM F-138 standard } \\
\text { Range (\%wt) }\end{array}$ & $\begin{array}{l}\text { Uncorroded } \\
\text { screw (\%wt) }\end{array}$ & $\begin{array}{c}\text { Corroded } \\
\text { screw (\%wt) }\end{array}$ \\
\hline $\mathrm{Cr}$ & Min 17.00; Max $19.00 \pm 0.20$ & 14.808 & 25.779 \\
\hline $\mathrm{Ni}$ & Min 13.00; Max $15.00 \pm 0.15$ & 9.144 & 15.496 \\
\hline Mo & Min 2.25; Max $3.00 \pm 0.10$ & 1.765 & 3.154 \\
\hline $\mathrm{Mn}$ & $\operatorname{Max} 2.00 \pm 0.04$ & 0.979 & 1.922 \\
\hline Co & - & 0.188 & 0.276 \\
\hline $\mathrm{Cu}$ & $\operatorname{Max} 0.50 \pm 0.03$ & 0.240 & 0.738 \\
\hline $\mathrm{Ti}$ & - & 0.006 & 0.009 \\
\hline $\mathrm{C}$ & $\operatorname{Max} 0.030 \pm 0.005$ & & \\
\hline $\mathrm{Si}$ & Max $0.75 \pm 0.05$ & & \\
\hline $\mathrm{N}$ & Max $0.10 \pm 0.01$ & & \\
\hline $\mathrm{P}$ & $\operatorname{Max} 0.025 \pm 0.005$ & & \\
\hline S & $\operatorname{Max} 0.010 \pm 0.005$ & & \\
\hline $\mathrm{PRE}=\% \mathrm{Cr}+3.3 * \% \mathrm{Mo}$ & $\mathrm{PRE} \geq 26$ & 20.632 & 36.187 \\
\hline
\end{tabular}




\subsection{Optical Microscopy Analysis}

Figure 5(a) and Figure 5(b) show the bright field images of the screws polished samples where it can be observing a fine massive precipitation throughout the corroded sample. In Figure 6(a) and Figure 6(b) are the dark field images of the as polished surfaces, and it shows the confirmation of a significant precipitation. On the other hand, the microstructures of the corroded and uncorroded screws are presented in Figure 7(a) and Figure 7(b), respectively. It is observed in Figure 7 (a) the failed screw shows a microstructure with a severe plastic deformation.
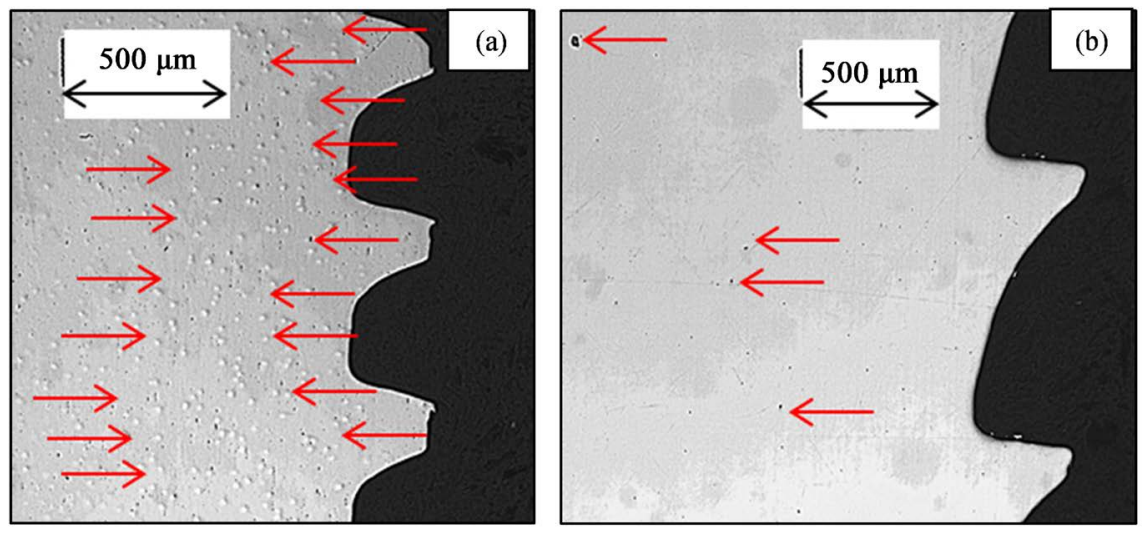

Figure 5. OM bright field images (a) corroded screw; (b) uncorroded screw.
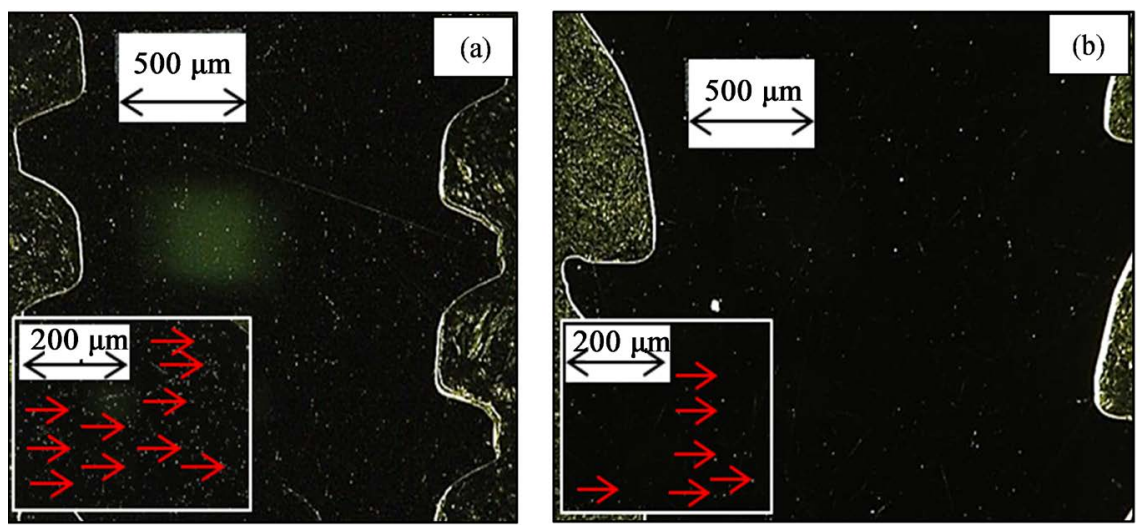

Figure 6. OM dark field images (a) corroded screw; (b) uncorroded screw.
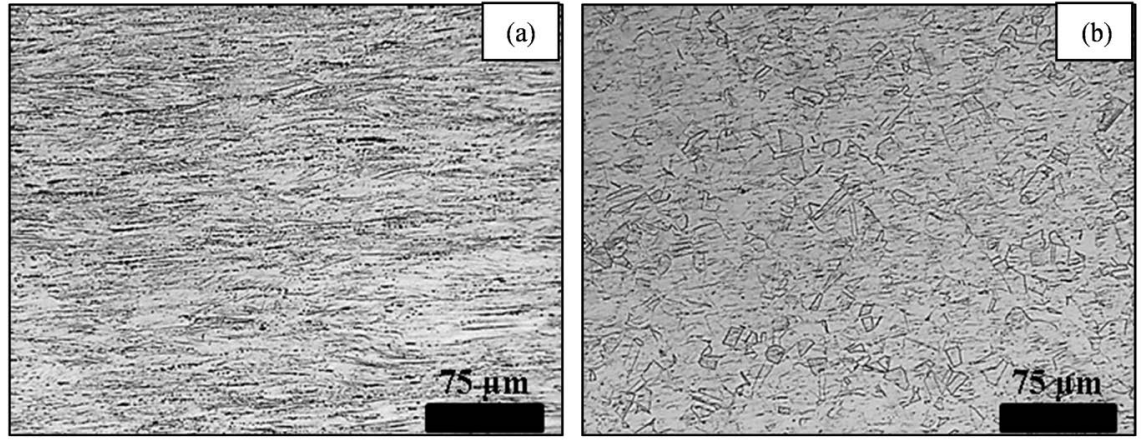

Figure 7. Microstructures OM bright field images (a) corroded screw; (b) uncorroded screw. 
In addition, by considering the higher $\mathrm{Cr}$ content, the formation of rich $\mathrm{Cr}$ precipitates is possible, as shown in Figure 5(a) and Figure 6(a), therefore higher corrosion susceptibility is possible.

In addition, the precipitation was evaluated by measuring its distribution and average size, using dark field images by OM and ImageJ software. Figure 8(a) and Figure $8(\mathrm{~b})$ show the results obtained of the precipitates area measurements, having an average diameter of $2.7 \mu \mathrm{m}$ and $2.4 \mu \mathrm{m}$ respectively, imply that there is not a substantial size difference. Furthermore, the measured precipitate fractions ratios were $1.1 \mathrm{E}-3$ and $1.4 \mathrm{E}-3$ for uncorroded and corroded samples, which validate the previous optical observations regarding fine precipitation.

\subsection{Scanning Electron Microscopy}

Due to the severe plastic deformation a cavity formation and a massive precipitation is induced throughout the entire sample, as shown in Figure 9(a) and Figure 9(b). Detailed images are shown in Figure 9(c) and Figure 9(d), it can be observed the deformations bands and the interactions of precipitates with the cavities (arrow point out). This suggests that the screws manufacturing process was cold wiredrawing. From all the results obtained in previous sections, it is possible to relate the corrosion failure to the severe deformation and the massive precipitation; this may be caused by cold wire-drawing process and the excessive stabilizing $\alpha$ alloying elements.

\subsection{Microhardness Test}

The Vickers microhardness test was performed on both screws in longitudinal (L) and transversal (T) direction. From the results obtained, the corroded sample showed higher values on both directions having $401 \mathrm{HV}$ T and $387 \mathrm{HV}$ L, compared with uncorroded sample $269 \mathrm{HV}$ T and $254 \mathrm{HV} \mathrm{L}$. There is a clear difference among the samples tested, as shown in Table 2 and as it was observed
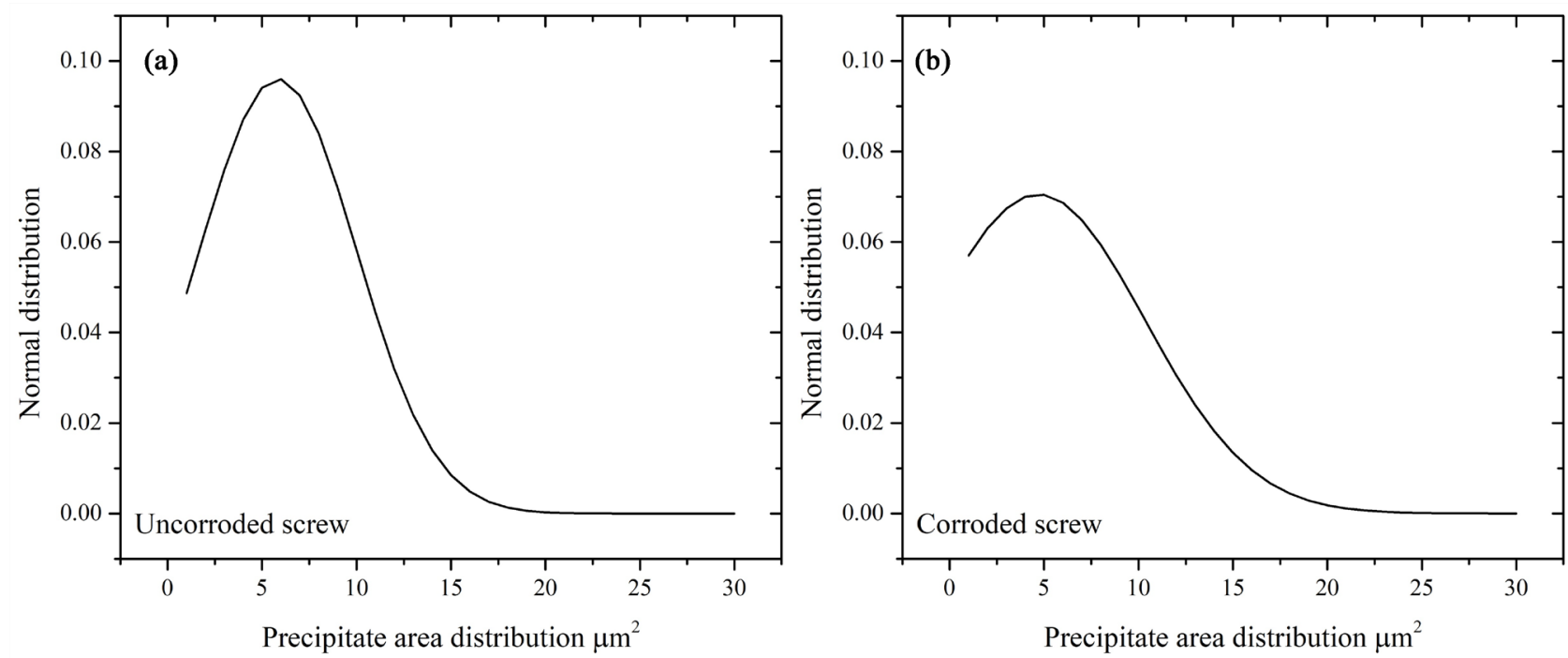

Figure 8. Precipitate size distribution as measured area (a) uncorroded screw, (b) corroded screw. 

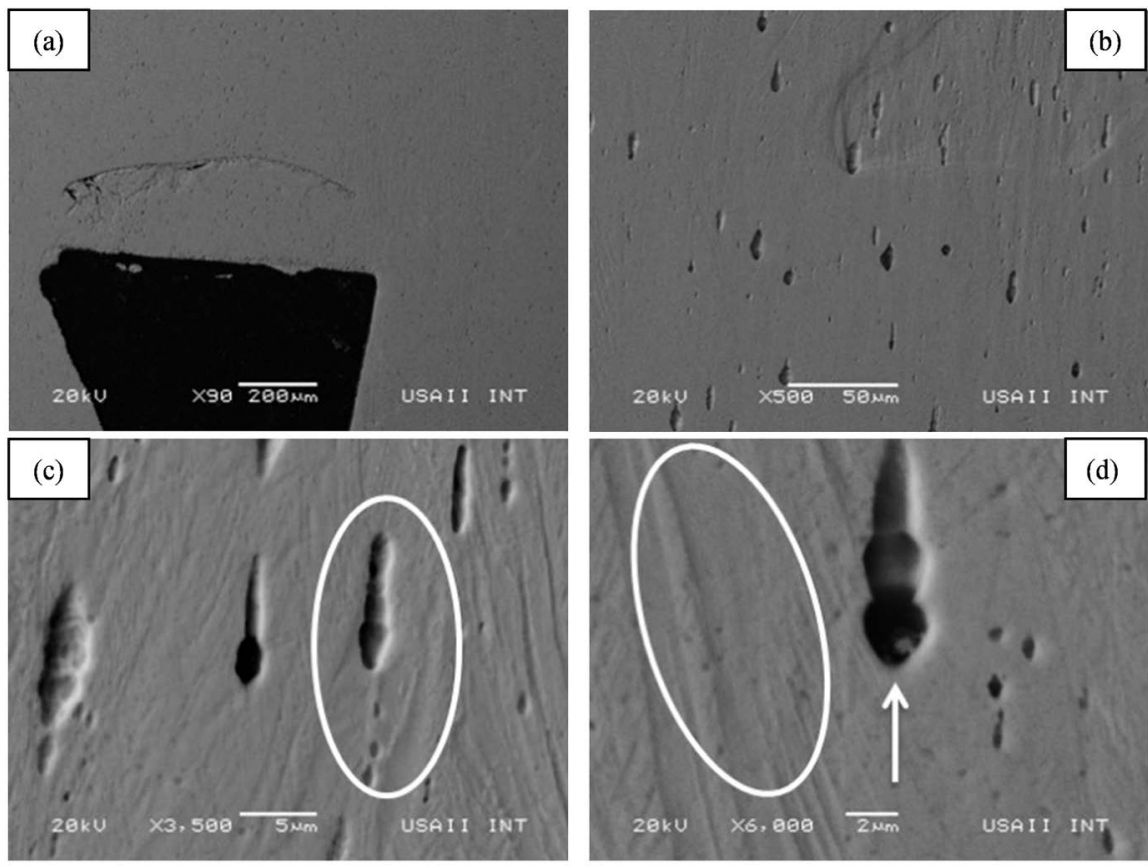

Figure 9. SEM images (a), (b), (c) and (d) of the corroded screw at different magnifications sizes.

Table 2. Results of the quantitative elemental analysis of the uncorroded and corroded screws.

\begin{tabular}{ccccc}
\hline Direction & $\begin{array}{c}\text { Corroded screw } \\
\text { (average) }\end{array}$ & $\begin{array}{c}\text { Standard } \\
\text { deviation }\end{array}$ & $\begin{array}{c}\text { Uncorroded screw } \\
\text { (average) }\end{array}$ & $\begin{array}{c}\text { Standard } \\
\text { deviation }\end{array}$ \\
\hline Longitudinal & 387 & 23.7 & 254 & 11.6 \\
Transversal & 401 & 6.78 & 269 & 7.8 \\
\hline
\end{tabular}

in the microstructure characteristics. The ASTM F-138 standard establishes for SS in annealing state a hardness of $250 \mathrm{HB}(263 \mathrm{HV})$, in the case of cold deformed steel, it does not stipulate a hardness value; the failed screw shows 401 HV due to severe plastic deformation.

\subsection{Results of the Prospection of Chemical Composition}

\subsubsection{Genetic Algorithm}

The implementation of heuristic methods such as GA in the material science field is important and its application lies in the possibility of optimizing manufacturing processes using parameters that affect the performance of the materials. Considering the restrictions of chemical composition stipulated by ASTM F-138 standard and the Schaeffler-Delong diagram a squared area was considered, as shown in Figure 11. The area proposed was found by genetic algorithms; the purpose was to obtain a fully austenitic alloy for better corrosion resistance properties. The restrictions applied in the genetic algorithm for Equations i.e. (1), (2) and (3) are presented below:

- $\mathrm{Cr}_{\mathrm{E}}$ and PRE number condition established by ASTM F-138 standard, where 
the $\mathrm{Cr}_{\mathrm{E}}$ and PRE are correlated.

$$
\begin{aligned}
& \text { PRE }\left\{\% \mathrm{Cr}_{\text {ASTM F138 }}+\left(3.3 * \% \mathrm{Mo}_{\text {ASTM F } 138}\right) \geq 26\right\} \\
&\left\{\mathrm{Min}_{\text {ASTM F138 }} \leq \% \mathrm{Cr} \leq \operatorname{Max}_{\text {ASTM F138 }}\right\}, \\
&\left\{\mathrm{Min}_{\text {ASTM F138 }} \leq \% \mathrm{Mo} \leq \operatorname{Max}_{\text {ASTM F138 }}\right\} \\
& \mathrm{Cr}_{\mathrm{E}}=\% \mathrm{Cr}+\% \mathrm{Mo}+(1.5 * \mathrm{Si}) \\
&\left\{\mathrm{Min}_{\mathrm{PRE}} \leq \% \mathrm{Cr} \leq \operatorname{Max}_{\mathrm{PRE}}\right\},\left\{\operatorname{Min}_{\mathrm{PRE}} \leq \% \mathrm{Mo} \leq \operatorname{Max}_{\mathrm{PRE}}\right\}, \\
&\left\{\mathrm{Min}_{\mathrm{DB}} \leq \mathrm{Si} \leq \mathrm{Max}_{\mathrm{ASTM} \mathrm{F} 138}\right\}
\end{aligned}
$$

- $\mathrm{Ni}_{\mathrm{E}}$ conditions

$$
\begin{aligned}
& \mathrm{Ni}_{\mathrm{E}}=\% \mathrm{Ni}+(30 * \% \mathrm{C})+(30 * \% \mathrm{~N})+(0.5 * \% \mathrm{Mn}) \\
& \left\{\operatorname{Min}_{\mathrm{ASTM} \mathrm{F} 138} \leq \% \mathrm{Ni} \leq \operatorname{Max}_{\text {ASTM F138 }}\right\},\left\{\operatorname{Min}_{\mathrm{DB}} \leq \% \mathrm{C} \leq \operatorname{Max}_{\mathrm{ASTM} \mathrm{F} 138}\right\}, \\
& \left\{\operatorname{Min}_{\mathrm{DB}} \leq \% \mathrm{~N} \leq \operatorname{Max}_{\mathrm{ASTM} F 138}\right\},\left\{\operatorname{Min}_{\mathrm{DB}} \leq \% \mathrm{Mn} \leq \operatorname{Max}_{\mathrm{ASTM} \mathrm{F} 138}\right\}
\end{aligned}
$$

The Where DB is related with the minimal value of the data base used [5]. Figure 10 shows the performance of the genetic algorithm applied to the latter restrictions. The black squares correspond to the best fitness value.

The resulting solutions were found being the best values obtained for the $\alpha$ and $\gamma$ stabilizing elements from the Equations (2) and (3); the minimum ( $₫$ ) and maximum $(\bullet)$ values are as follows:

$$
\begin{aligned}
& 20.265<\mathrm{Cr}_{\mathrm{E}}<22 \\
& 18<\mathrm{Ni}_{\mathrm{E}}<20.43
\end{aligned}
$$

The blue area of Figure 11 comprises the restrictions of alloy elements stipulated by ASTM F-138 standard. In Figure 11 the proposed area (green area) is shown, considering the earlier mentioned restrictions. The alloying contents were restricted to ensure a fully austenitic alloy (proposed area).

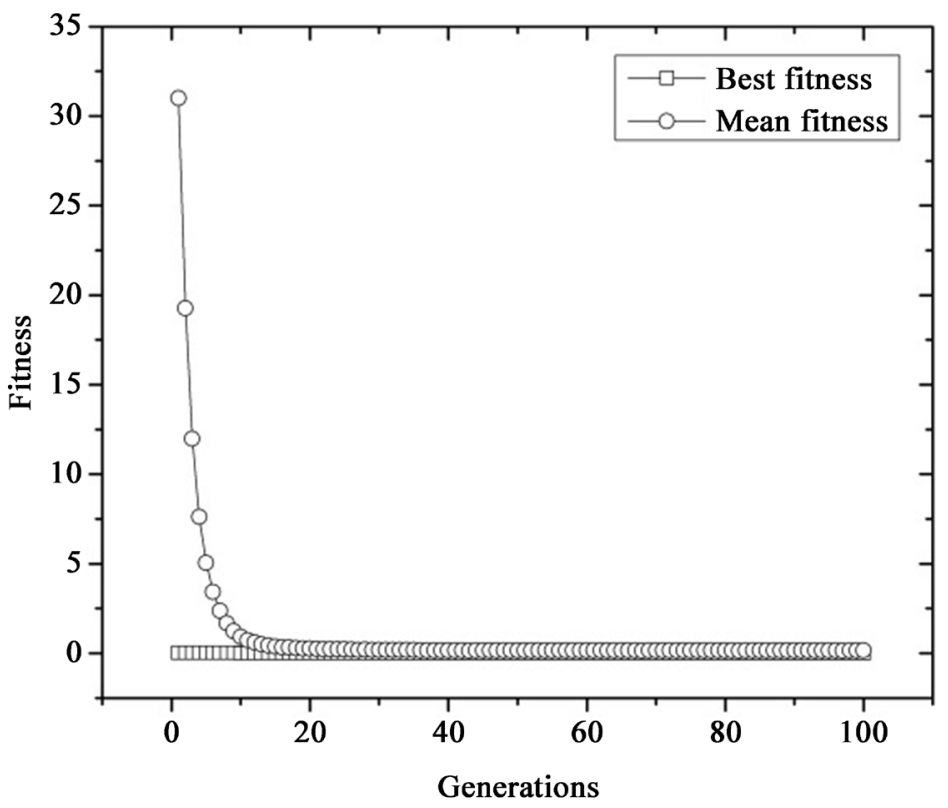

Figure 10. Genetic algorithm performance. 


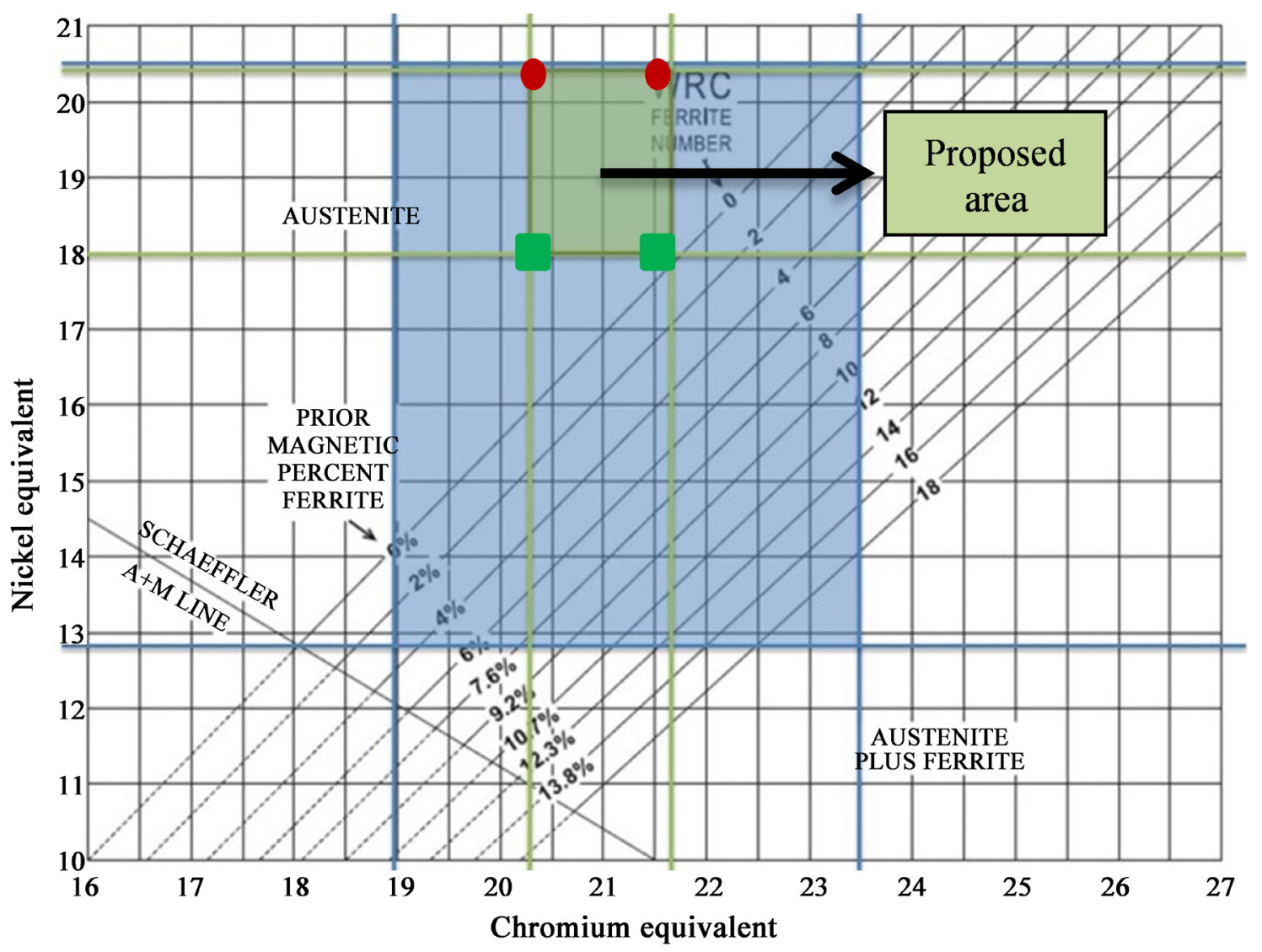

Figure 11. Area of the chemical composition proposed.

Table 3. Proposed chemical composition ranges.

\begin{tabular}{cccccccccc}
\hline $\begin{array}{c}\text { Element } \\
\text { (\%wt) }\end{array}$ & $\mathbf{C}$ & $\mathbf{N}$ & $\mathbf{S i}$ & $\mathbf{M n}$ & $\mathbf{P}$ & $\mathrm{S}$ & $\mathrm{Ni}$ & $\mathrm{Cr}$ & $\mathrm{Mo}$ \\
\hline Maximum & 0.035 & 0.107 & 0.400 & 2.04 & 0.025 & 0.002 & 15.15 & 18.70 & 2.70 \\
Minimum & 0.025 & 0.060 & 0.010 & 1.50 & 0.004 & 0.0002 & 14.70 & 17.75 & 2.50 \\
\hline
\end{tabular}

Table 3 shows the ranges obtained by GA for the alloy content that accomplishes the restrictions of standard. Also, this proposal is in the austenitic zone on the Schaeffler-Delong diagram. It would be expected that the alloy conditions meet the requirements of corrosion resistance and finally avoid the failure due to the massive formation of precipitates.

\subsubsection{Mapping of the Proposed Chemical Composition Ranges}

The SFE was mapped using artificial neural networks over the selected area by genetic algorithms. It has been reported that an increase in SFE indicates an accumulation of defects on the crystal lattice particularly in SS alloys where sensitization is induced [5] [9]-[15]. Therefore, obtaining the predicted values of SFE on the proposed area is a very useful tool to analyze its behavior as a function of the proposed alloy content ranges. The prediction performance of the ANN as shown in Figure 12 was used for the SFE mapping. 


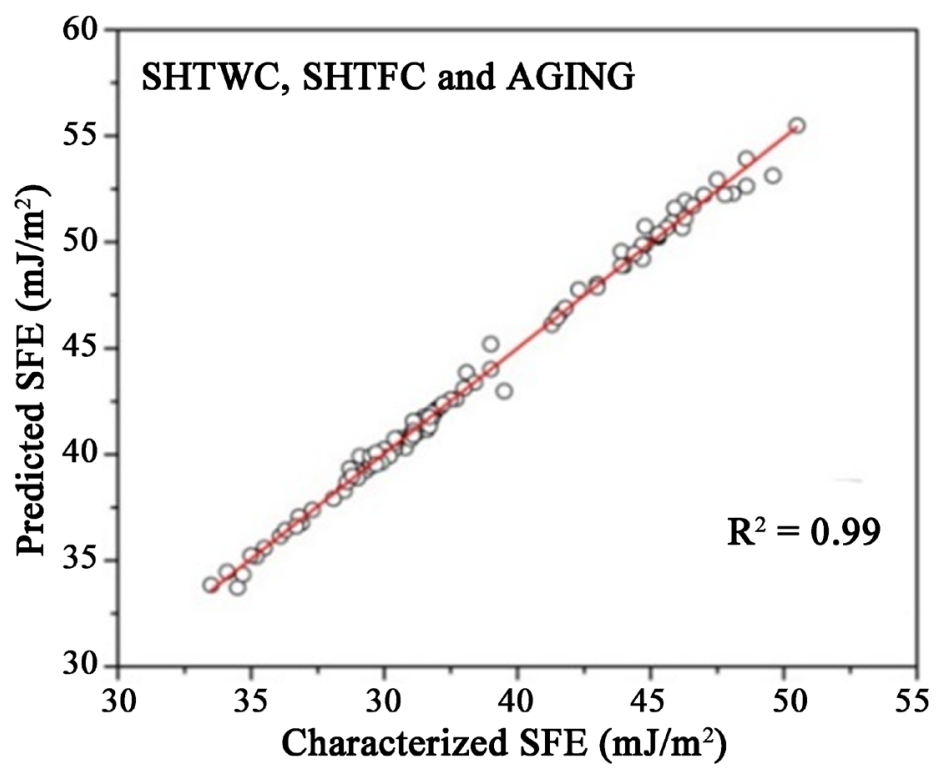

Figure 12. Comparison between predicted and characterized SFE values.

Because the ANN was trained for the prediction of SFE for three different heat treatments, it is feasible to observe the behavior of each one and additionally propose an adequate, subsequent to the manufacturing process. The following Figures show the SFE behavior of the three different heat treatments. The SHTWC and SHTFC exhibit different behaviors but similar SFE maximum value, as shown in Figure 13(a) and Figure 13(b). The main difference lies on the formation of defects due to the thermal process which is enclosed in a chemical composition range. Finally, the results for AGING treatment are presented in Figure 13(c), there is an increase in SFE that can be related to the formation of small precipitates; this has been experimentally reported [5]. The thermal process suggested is SHTWC due to its effect on SFE and its correlation with microstructure, precipitates, and mechanical properties, these confirms previously results published [1] [3] [5]. The predictive model by ANN can provide support for the design and optimizations of the surgical austenitic stainless steel.

\section{Discussion}

Initially, it was found a deviation from the ASTM F-138 standard in relation directly to the screws involved with their chemical composition as shown in Table 1. It is clear that the difference is related to the chemical composition, specifically in $\mathrm{Cr}, \mathrm{Ni}$ and Mo contents. It is well known that these elements have great influence on the corrosion resistance [1] [2] [4]-[9]. However, the screws analyzed did not fulfill the chemical composition required, but despite this statement, only one screw failed, mainly related to its manufacturing process that induced severe plastic deformation. On the other hand, the hardness difference obtained between screws is considerable possibly due to the manufacturing process and the induced precipitation [5] [6] [7] [8] [9]. According to Perumal et al. 2020 [25], several techniques for severe plastic deformation have been reported such 


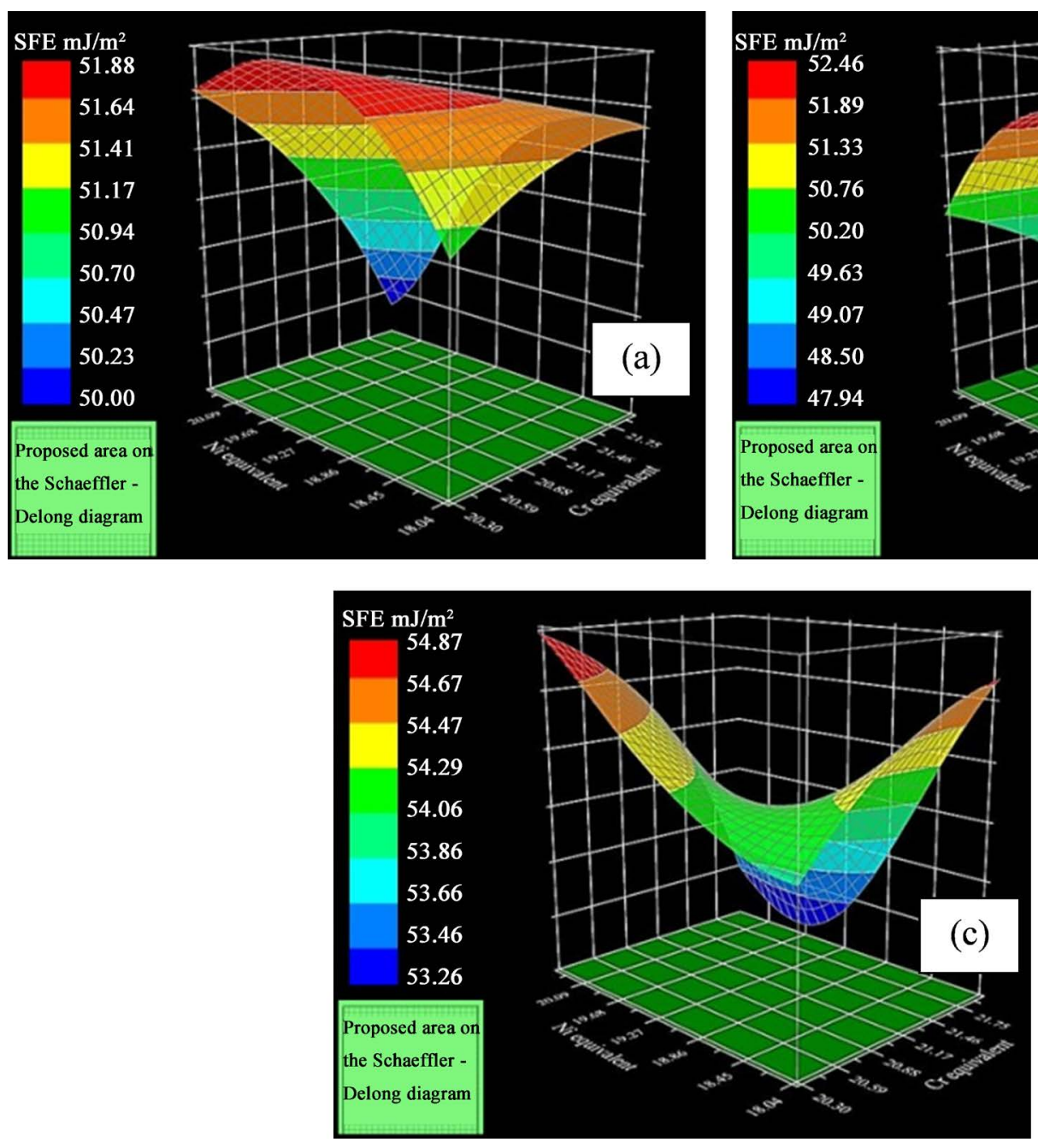

Figure 13. Mapping of SFE (a) SHTWC, (b) SHTFC, and (c) AGING.

as friction stir processing (FSP), severe shot peening, warm multi-axial forging, equal channel angular pressing (ECAP) and high-pressure torsion (HPT). Consequently, this process modifies the microstructure through the formation of the martensitic phase $(\mathcal{E})$ and the fracture behavior of the passive layer formed $\left(\mathrm{Cr}_{2} \mathrm{O}_{3}\right)$. Also, it has been reported that the deformation process may induce the possibility of improving mechanical properties and corrosion resistance through grain refinement [25] [26] [27] [28]. However, in the present study, the deformation process was not controlled, but a highly deformed microstructure was observed, and higher microhardness values were obtained, in conjunction with the breakdown of the passive $\mathrm{Cr}_{2} \mathrm{O}_{3}$ layer. Additionally, it is likely that the transformation of the austenitic phase into two different phases has been induced, as the reaction: $\gamma_{1} \rightarrow \varepsilon \rightarrow \alpha^{\prime}$, which causes a localized difference in corrosion potentials, forming an anode and cathode reaction, reducing corrosion resistance [29] [30]. This is because the $\varepsilon$ and $\alpha^{\prime}$ phases are stable at low temperature, so it can be induced by thermomechanical treatments processes [29] [30] [31] [32]. On the other hand, based on the deformation bands shown in Figure 9 and the re- 
sults obtained by Chen et al. 2021 [33], the formation of "patchy heterogeneous regions" is possible, which generates localized variations in the electrochemical potentials on the surface, inducing micro-galvanic cell corrosion. Despite the inevitable plastic deformation during the manufacturing process, recently $\mathrm{Ku}$ mar et al. 2020 [34], reported a more protective passive layer derived from the application of solution annealing heat treatments after plastic deformation. Therefore, the proposal presented in the present work considers the manufacture of the alloy from its chemical composition and the deformation process. Suggesting in the case of being inevitably the necessary severe plastic deformation derived from the corresponding manufacturing process, further treatment processes as solubilization and rapid cooling must be performed to induce the microstructure recrystallization as shown in Figure 15. In addition, according to recent works, it dissolves the martensitic phases and obtains a more protective passive layer [34].

Regarding the GA and ANNs employed, a potential proposal of chemical composition on the performance of stainless steel as a function of the ASTM F-138 standard and the microstructure predicted by the Schaeffler-Delong diagram was performed. The chemical composition ranges proposed are based in the standard and the diagram; however, it is also correlated with the formation of second-phase particles such as precipitates at the grain boundaries. The precipitates formed are related to carbides produced as a consequence of the rapid diffusion of $\mathrm{Cr}$ at the grain boundaries and its interaction with $\mathrm{C}$. The most common carbides found in this type of alloys are $\mathrm{M}_{7} \mathrm{C}_{3}$ and $\mathrm{M}_{23} \mathrm{C}_{6}$ (structures $\mathrm{D} 10_{1}$ and $\mathrm{D} 8_{4}$ of the Pnma and $\mathrm{Fm}(-3) \mathrm{m}$ space groups, respectively) either in transgranular form and/or along the grain boundaries [35] [36]. If massive precipitation is formed, intergranular corrosion or sensitization is induced [37] [38] [39]. Therefore, the control of the chemical composition in regard to $\mathrm{Cr}$ and $\mathrm{C}$ is very important. On the other hand, the solidification in the manufacturing process directly affects the formation of precipitates. Based in the work of Wieczerzak et al. 2016 [40] and in calculated phase diagrams using the CALPHAD software (see Figure 14(a) and Figure 14(b)), the precipitation sequence for the manufacture of surgical components similar to the studied in this work can be as follows: Liquid $\left(\approx 1500^{\circ} \mathrm{C}\right) \rightarrow$ Liquid $+\alpha_{1}\left(\approx 1450^{\circ} \mathrm{C}\right) \rightarrow \alpha_{1}\left(\approx 1350^{\circ} \mathrm{C}\right) \rightarrow \gamma_{2}+\alpha_{1}$ $\left(\approx 1200^{\circ} \mathrm{C}\right) \rightarrow \gamma_{1}+\alpha_{1}+\sigma\left(\approx 1100^{\circ} \mathrm{C}\right) \rightarrow \gamma_{1}+\sigma\left(\approx 1000^{\circ} \mathrm{C}\right) \rightarrow \gamma_{2}+\mathrm{M}_{23} \mathrm{C}_{6}+\sigma$ $\left(\approx 700^{\circ} \mathrm{C}\right) \rightarrow \gamma_{1}+\alpha_{1}+\mathrm{M}_{23} \mathrm{C}_{6}+\sigma\left(\approx 500^{\circ} \mathrm{C}\right) \rightarrow \gamma_{2}+\alpha_{1}+\alpha_{2}+\mathrm{M}_{23} \mathrm{C}_{6}+\mathrm{P}\left(\approx 400^{\circ} \mathrm{C}\right) \rightarrow$ $\gamma_{1}+\alpha_{1}+\alpha_{2}+\mathrm{M}_{23} \mathrm{C}_{6}+\mathrm{P}\left(\approx 200^{\circ} \mathrm{C}\right)$. Where the formation of the $\sigma$ phase generally occurs at $\approx 1100^{\circ} \mathrm{C}$ and above $20 \%$ weight of $\mathrm{Cr}$, it must be avoided because it is a detrimental phase [40]. According to the ranges established by the ASTM F-138 standard related to the main system ( $\mathrm{Fe}-\mathrm{Cr}-\mathrm{Ni}-\mathrm{Mo}-\mathrm{C})$, the predominant phase is A1 $\left(\gamma_{1}\right)$. It can be assumed that the phases present in the alloy manufactured in agreement with the standard are: $\gamma_{1}+\alpha_{1}+\mathrm{M}_{23} \mathrm{C}_{6}$, although due to the carbon content, the amount of $\mathrm{M}_{23} \mathrm{C}_{6}$ precipitates can be minimum, moreover, the $\alpha_{1}$ phase is expected to be practically undetectable. As a result, the material must be 


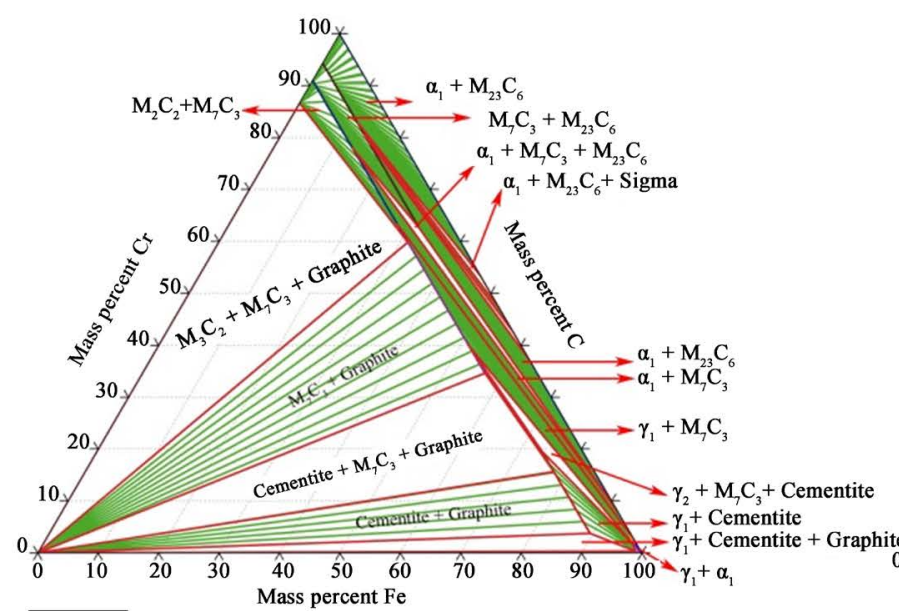

(a)

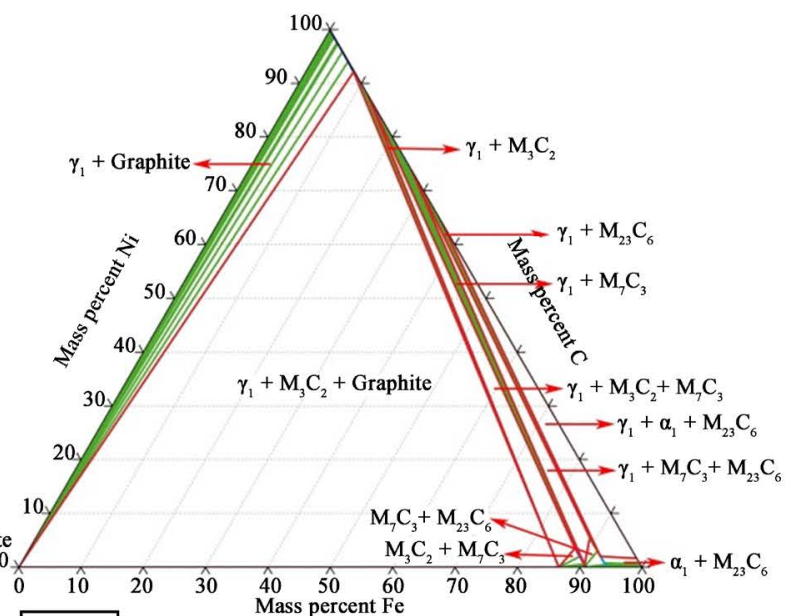

(b)

Figure 14. Ternary phase diagrams at $800^{\circ} \mathrm{C}$ (a) Fe-Cr-C, (b) Ni-Cr-C.

composed by entirely austenitic microstructure, having the benefits of $\mathrm{NiO}$ and $\mathrm{Cr}_{2} \mathrm{O}_{3}$ compounds as protective agents against corrosion. Where the $\mathrm{NiO}$ forms a continuous layer while the $\mathrm{Cr}_{2} \mathrm{O}_{3}$ is formed mainly at grain boundaries due to the rapid diffusion rate of $\mathrm{Cr}$ [41]. Regarding to Mo, it does not form detrimental phases; it is added to increase corrosion resistance. On the other hand, heat treatment is crucial in the resulting microstructure, in this type of alloy, the massive distribution of structures $\mathrm{D} 10_{1}$ and $\mathrm{D} 8_{4}$ can be formed with an isothermal treatment at $\approx 800^{\circ} \mathrm{C}$ from an extended period of time. Usually in similar systems which are not for surgical use and require excellent mechanical properties, an aging treatment is applied at an appropriate temperature for the formation of precipitates on the grain boundary [35] [39]. Nevertheless, this type of treatment should be avoided in the system studied in this work, that is, is mandatory to avoid the exposition of the alloy to the precipitation temperature, hence, the rapid cooling is the best option. It has been reported that the precipitates distribution and the increase along grain boundaries can be controlled employing heat treatments methods [36]. Experimentally, the effect of carbide formation on the microstructure can be observed as shown in Figure 15. In Figure 15(a) and Figure 15(b) it is feasible to observe a microstructure with lower concentration of micrometric precipitates. In the case of furnace cooling, it is possible that a greater number of precipitates will form at the grain boundary (indicated by red arrows). On the other hand, Figure 15(c) shows a sensitized microstructure, formed by applying an aging heat treatment for 1 hour at $800^{\circ} \mathrm{C}$. Thus, based in the former analysis, the control of the chemical composition and heat treatment is very important. The implementation of GA in the prospection of chemical composition was useful to obtain an ideal area on the Schaeffler-Delong diagram and for the modification of the chemical composition ranges. In the present work, the resulting proposal comprises the austenitic area of the Schaeffler-Delong diagram, the chemical composition established in 

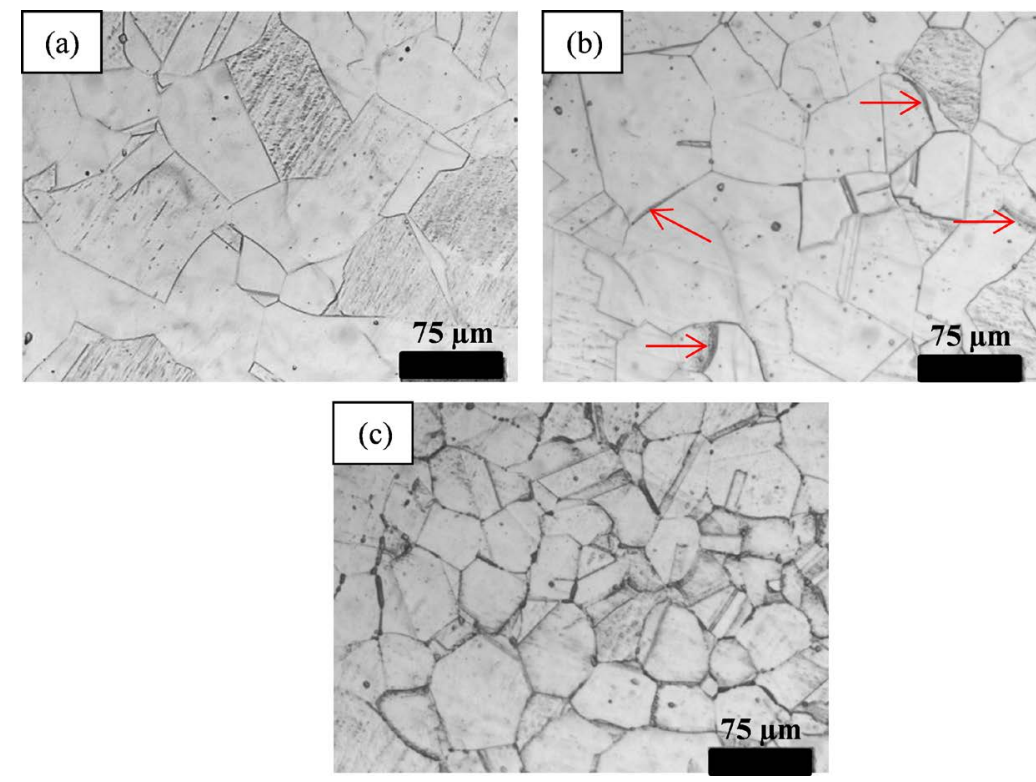

Figure 15. Ternary Microstructures of 316 stainless steel (a) solubilization-water cooling, (b) solubilization-furnace cooling, (c) solubilization-aging treatment. Where the solubilization and aging treatments were applied at $1000^{\circ} \mathrm{C}$ and $800^{\circ} \mathrm{C}$, respectively.

the ASTM F-138 standard and the phase analysis that would mainly contain the $\gamma_{1}+\alpha_{1}+\mathrm{M}_{23} \mathrm{C}_{6}$ phases, being the $\mathrm{A} 1$ phase corrosion protected by $\mathrm{NiO}$ and $\mathrm{Cr}_{2} \mathrm{O}_{3}$. In consideration to the predictive model, performed by ANNs, this can provide reinforcement for the design and optimization of surgical austenitic stainless steel; however, it is necessary to conduct experimental tests for this proposal which would complement the results obtained.

\section{Conclusions}

The corrosion failure was associated with severe plastic deformation and the presence of precipitates. The quantitative elemental analysis by atomic absorption confirmed that both implants contain the same alloy elements but different concentrations. Based on the ASTM F-138 standard, both screws did not accomplish the chemical composition restrictions which justifies that the corrosion failure could be generated. The Vickers microhardness test showed that the corroded screw had greater mechanical properties than the uncorroded screw.

On the other hand, using genetic algorithms, considering the chemical composition and thermal analysis regarding the established restriction by the ASTM F-138 standard and the Schaeffler-Delong diagram, new chemical composition ranges were proposed. It was possible to outline the ranges propose to predict the SFE values for the three thermal process conditions using ANN. The range proposed must avoid the massive precipitates formation and $\alpha$ phase.

\section{Acknowledgements}

Román-Sedano A. Monzamodeth acknowledges the $\mathrm{PhD}$ scholarship support from CONACYT (CVU: 828336) and the technical support of H. H. Hinojosa Galvan 
and E. Vázquez from ICF-UNAM and G. Aramburo, S. García, I. Puente and I. Reyes from FQ-UNAM. Moreover, the authors acknowledge the support of the PAPIIT-UNAM project (ID IT102619).

\section{Conflicts of Interest}

The authors declare no conflicts of interest regarding the publication of this paper.

\section{References}

[1] Roman, A., Campillo, B., Martínez, H. and Flores, O. (2019) Prediction of the Stacking Fault Energy in Austenitic Stainless Steels Using an Artificial Neural Network. International Journal of Engineering and Technology Research, 9, 31-38. https://doi.org/10.31873/IJETR.9.1.2019.18

[2] Gervais, B., Vadean, A., Raison, M. and Brochu, M. (2016) Failure Analysis of a 316L Stainless Steel Femoral Orthopedic Implant. Case Studies in Engineering Failure Analysis, 5, 30-38. https://doi.org/10.1016/j.csefa.2015.12.001

[3] Román-Sedano, A.M. (2018) Study of Stainless Steel 3161 for Surgical Use. Master's Thesis. CIICAp-UAEM, Cuernavaca. (In Spanish)

[4] Thapa, N., Prayson, M. and Goswami, T. (2016) A Failure Study of a Locking Compression Plate Implant. Engineering Failure Analysis, 3, 68-72. https://doi.org/10.1016/j.csefa.2015.03.004

[5] Toshio, Y., Ken, S., Suguru, O. and Atsushi, H. (2013) The Effect of Chemical Composition and Heat Treatment Conditions on Stacking Fault Energy for Fe-Cr-Ni Austenitic Stainless Steel. Metallurgical and Materials Transactions A, 44, 5884-5896. https://doi.org/10.1007/s11661-013-1943-0

[6] Mumtaz, K., Takahashi, S., Echigoya, J., Kamada, Y., Zhang, L.F., Kikuchi, H. and Sato, K.A. (2004) Magnetic Measurements of Martensitic Transformation in Austenitic Stainless Steel after Room Temperature Rolling. Journal of Materials Science, 39, 85-97. https://doi.org/10.1023/B:JMSC.0000007731.38154.e1

[7] Pradhan, L.S.K., Bhuyan, P. and Mandal, S. (2019) Influence of the Individual Microstructural Features on Pitting Corrosion in Type 304 Austenitic Stainless Steel. Corrosion Science, 158, Article ID: 108091. https://doi.org/10.1016/j.corsci.2019.108091

[8] Tokita, S., Kokawa, H., Kodama, S., Sato, Y.S., Sano, Y., Li, Z., Feng, K. and Wu, Y. (2020) Suppression of Intergranular Corrosion by Surface Grain Boundary Engineering of 304 Austenitic Stainless Steel Using Laser Peening plus Annealing. Materials Today Communications, 25, Article ID: 101572. https://doi.org/10.1016/j.mtcomm.2020.101572

[9] Molnára, D., Sun, X., Lu, S., Li, W., Engberg, G. and Vitos, L. (2019) Effect of Temperature on the Stacking Fault Energy and Deformation Behaviour in 316L Austenitic Stainless Steel. Materials Science and Engineering. A, 759, 490-497. https://doi.org/10.1016/j.msea.2019.05.079

[10] Pierce, D., Bentley, J., Jimenez, J. and Wittig, J. (2012) Stacking Fault Energy Measurements of Fe-Mn-Al-Si Austenitic Twinning-Induced Plasticity Steels. Microscopy and Microanalysis, 17, 1888-1889. https://doi.org/10.1016/j.scriptamat.2012.01.050

[11] Moallemi, M., Hanzaki, A.Z. and Mirzaei, A. (2015) On the Stacking Fault Energy Evaluation and Deformation Mechanism of Sanicro-28 Super-Austenitic Stainless 
Steel. Journal of Materials Engineering and Performance, 24, 2335-2340. https://doi.org/10.1007/s11665-015-1501-6

[12] Kang, M., Woo, W., Lee, Y.K. and Seong, B.S. (2012) Neutron Diffraction Analysis of Stacking Fault Energy in Fe-18Mn-2Al-0.6C Twinning-Induced Plasticity Steels. Materials Letters, 76, 93-95. https://doi.org/10.1016/j.matlet.2012.02.075

[13] Walter, M., Roncery, L.M., Weber, S., Leich, L. and Theisen, W. (2020) XRD Measurement of Stacking Fault Energy of Cr-Ni Austenitic Steels: Influence of Temperature and Alloying Elements. Journal of Materials Science, 55, 13424-13437. https://doi.org/10.1007/s10853-020-04953-4

[14] Meric De Bellefon, G., Van Duysen, J.C. and Sridharan, K. (2017) CompositionDependence of Stacking Fault Energy in Austenitic Stainless Steels through Linear Regression with Random Intercepts. Journal of Nuclear Materials, 492, 227-230. https://doi.org/10.1016/j.jnucmat.2017.05.037

[15] Das, A. (2015) Revisiting Stacking Fault Energy of Steels. Metallurgical and Materials Transactions $A, 47,748-768$. https://doi.org/10.1007/s11661-015-3266-9

[16] Abbas, A.T., Abubakr, M., Hassan, M.A., Luqman, M., Soliman, M.S. and Hegab, H. (2020) An Adaptive Design for Cost, Quality and Productivity-Oriented Sustainable Machining of Stainless Steel 316. Journal of Materials Research and Technology, 9 , 16410-16422. https://doi.org/10.1016/j.jmrt.2020.10.056

[17] Mani, C., Karthikeyan, R., Kannan, S. and Periasamy, C. (2020) Optimization of Tensile Properties of 316L Stainless Steel and Monel 400 Weld Joints Using Genetic Algorithm. Materials Today Proceedings, 27, 2846-2851.

https://doi.org/10.1016/j.matpr.2020.01.250

[18] Zakeri, M., Bahrami, A. and Mousavi, S.H. (2007) Using Genetic Algorithm in Heat Treatment Optimization of 17-4PH Stainless Steel. Materials \& Design, 28, 2034-2039. https://doi.org/10.1016/j.matdes.2006.06.006

[19] Narayana, P.L., Lee, S.W., Park, C.H., Yeoma, J.T., Hong, J.K., Maurya, A.K. and Reddy, N.S. (2020) Modeling High-Temperature Mechanical Properties of Austenitic Stainless Steels by Neural Networks. Computational Materials Science, 179, Article ID: 109617. https://doi.org/10.1016/j.commatsci.2020.109617

[20] Wang, X. and Xiong, W. (2021) Stacking Fault Energy Prediction for Austenitic Steels: Thermodynamic Modeling vs. Machine Learning. Science and Technology of Advanced Materials, 21, 626-634. https://doi.org/10.1080/14686996.2020.1808433

[21] Feng, S. and Dong, H.B. (2020) Predicting Solidification Cracking Susceptibility of Stainless Steels Using Machine Learning. IOP Conference Series: Materials Science and Engineering, 861, Article ID: 012073. https://doi.org/10.1088/1757-899X/861/1/012073

[22] Liu, B., Jin, W., Lu, A., Liu, K., Wang, C. and Mi, G. (2020) Optimal Design for Dual Laser Beam Butt Welding Process Parameter Using Artificial Neural Networks and Genetic Algorithm for SUS316L Austenitic Stainless Steel. Optics \& Laser Technology, 125, Article ID: 106027. https://doi.org/10.1016/j.optlastec.2019.106027

[23] Feng, W. and Yang, S. (2016) Thermomechanical Processing Optimization for 304 Austenitic Stainless Steel Using Artificial Neural Network and Genetic Algorithm. Applied Physics A, 122, 1018. https://doi.org/10.1007/s00339-016-0546-1

[24] Hagan, M.T. and Menhaj, M.B. (1994) Training Feedforward Networks with the Marquardt Algorithm. IEEE Transactions on Neural Networks, 5, 989-993. https://doi.org/10.1109/72.329697

[25] Perumal, G., Grewal, H.S. and Arora, H.S. (2020) Enhanced Durability, Bio-Activity and Corrosion Resistance of Stainless Steel through Severe Surface Deformation. 
Colloids and Surfaces B: Biointerfaces, 194, Article ID: 111197. https://doi.org/10.1016/j.colsurfb.2020.111197

[26] Srinivasan, N., Kain, V., Birbilis, N., Sunil Kumar, B., Gandhi, M.N., Sivaprasad, P.V., Chai, G., Lodh, A., Ahmedabadi, P.M. and Samajdar, I. (2016) Plastic Deformation and Corrosion in Austenitic Stainless Steel: A Novel Approach through Microtexture and Infrared Spectroscopy. Corrosion Science, 111, 404-413. https://doi.org/10.1016/j.corsci.2016.05.027

[27] Guan, L., Ye, Z.X., Yang, X.Y., Cai, J.M., Li, Y., Li, Y., Zhang, Y.K. and Wang, G. (2021) Pitting Resistance of 316 Stainless Steel after Laser Shock Peening: Determinants of Microstructural and Mechanical Modifications. Journal of Materials Processing Technology, 294, Article ID: 117091. https://doi.org/10.1016/j.jmatprotec.2021.117091

[28] Ferreira, R.P., Nascimento, C.C.F., Reis, G.S., Silva, E.S. and Rodrigues, S.F. (2020) Thermomechanical Behavior and Corrosion Resistance of a 316 L Austenitic Stainless Steel. Materials Sciences and Applications, 11, 217-233. https://doi.org/10.4236/msa.2020.114015

[29] Solomon, N. and Solomon, I. (2017) Effect of Deformation-Induced Phase Transformation on AISI 316 Stainless Steel Corrosion Resistance. Engineering Failure Analysis, 79, 865-875. https://doi.org/10.1016/j.engfailanal.2017.05.031

[30] Grigull, S. (2003) Tensile Deformation Induced Texture Transformation in Austenitic Stainless Steel. Textures and Microstructures, 35, 153-162. https://doi.org/10.1080/07303300310001628616

[31] Huang, C.X., Yang, G., Gao, Y.L., Wu, S.D. and Li, S.X. (2007) Investigation on the Nucleation Mechanism of Deformation-Induced Martensite in an Austenitic Stainless Steel under Severe Plastic Deformation. Journal of Materials Research, 22, 724-729. https://doi.org/10.1557/jmr.2007.0094

[32] Nakada, N., Ito, H., Matsuoka, Y., Tsuchiyama, T. and Takaki, S. (2010) Deformation-Induced Martensitic Transformation Behavior in Cold-Rolled and Cold-Drawn Type 316 Stainless Steels. Acta Materialia, 58, 895-903. https://doi.org/10.1016/j.actamat.2009.10.004

[33] Chen, X., Gussev, M., Balonis, M., Bauchy, M. and Sant, G. (2021) Emergence of Micro-Galvanic Corrosion in Plastically Deformed Austenitic Stainless Steels. Materials \& Design, 203, Article ID: 109614. https://doi.org/10.1016/j.matdes.2021.109614

[34] Kumar, V., Kumar Gupta, R. and Das, G. (2020) Influence of Deformation and Annealing on Microstructure and Corrosion Behavior of Austenitic Stainless Steel. Materials Today: Proceedings, 22, 3347-3352.

https://doi.org/10.1016/j.matpr.2020.03.361

[35] Ren, Z. and Ernst, F. (2020) High-Temperature Phase Transformations in AISI 316 Stainless Steel Infused with Concentrated Interstitial Carbon. Journal of Alloys and Compounds, 819, Article ID: 153000. https://doi.org/10.1016/j.jallcom.2019.153000

[36] Gorunov, A.I. (2020) Investigation of $\mathrm{M}_{7} \mathrm{C}_{3}, \mathrm{M}_{23} \mathrm{C}_{6}$ and $\mathrm{M}_{3} \mathrm{C}$ Carbides Synthesized on Austenitic Stainless Steel and Carbon Fibers Using Laser Metal Deposition. Sur face and Coatings Technology, 401, Article ID: 126294. https://doi.org/10.1016/j.surfcoat.2020.126294

[37] Cheng, C.Q., Klinkenberg, L.I., Ise, Y., Zhao, J., Tada, E. and Nishikata, A. (2017) Pitting Corrosion of Sensitised Type 304 Stainless Steel under Wet-Dry Cycling Condition. Corrosion Science, 118, 217-226. https://doi.org/10.1016/j.corsci.2017.02.010 
[38] Javidi, M., Saleh, H.S.M. and Shariat, M.H. (2020) $\mathrm{CO}_{2}$ Corrosion Behavior of Sensitized 304 and 316 Austenitic Stainless Steels in 3.5 wt.\% NaCl Solution and Presence of $\mathrm{H}_{2} \mathrm{~S}$. Corrosion Science, 163, Article ID: 108230.

https://doi.org/10.1016/j.corsci.2019.108230

[39] Fujii, T., Tohgo, K., Mori, Y. and Shimamura, Y. (2018) Crystallography of Intergranular Corrosion in Sensitized Austenitic Stainless Steel. Materials Characterization, 144, 219-226.

[40] Wieczerzak, K., Bała, P., Cios, G., Tokarski, T., Górecki, K. and Frocisz, Ł. (2016) Experimental Study of Phase Transformation in Non-Equilibrium Hypoeutectic Alloy from the Fe-Cr-Ni-Mo-C System. Journal of Thermal Analysis and Calorimetry, 127, 449-455. https://doi.org/10.1007/s10973-016-5943-3

[41] Ferguson, J.B. and Lopez, H.F. (2006) Oxidation Products of Inconel Alloys 600 and 690 in Pressurized Water Reactor Environments and Their Role in Intergranular Stress Corrosion Cracking. Metallurgical and Materials Transactions A, 37, 2471-2479. https://doi.org/10.1007/BF02586220 